\title{
O PAPEL DO BANCO NACIONAL DE DESENVOLVIMENTO ECONÔMICO E SOCIAL COMO FINANCIADOR DOS INVESTIMENTOS DE LONGO PRAZO: O CASO DO GRUPO EBX - BRASIL
}

\author{
THE ROLE OF NATIONAL BANK FOR ECONOMIC AND \\ SOCIAL DEVELOPMENT AS FINANCIER LONG-TERM \\ INVESTMENTS: THE CASE OF THE EBX GROUP - BRAZIL
}

\author{
Claudia de Oliveira \\ Instituto Federal Fluminense - RJ - Brasil
}

\begin{abstract}
Resumo: O Banco Nacional de Desenvolvimento Econômico e Social (BNDES) vem desempenhando um papel relevante com os financiamentos de longo prazo às grandes empresas privadas nacionais, a partir dos anos 2000. Mesmo após as privatizações, quando deixou de ser o Estado-empresário, o setor público continua sendo importante ordenador da estrutura produtiva brasileira. Este artigo analisa como o BNDES, a subsidiária de participação acionária BNDESPAR, os fundos de pensão e as empresas privadas são atores centrais na compreensão das redes de proprietários no Brasil. A expansão do grupo EBX em setores estratégicos, os dados apresentados sobre os desembolsos do BNDES e as importantes alianças políticas do empresário Eike Batista ajudam a ilustrar a dinâmica de laços entre Estado e empresas privadas nacionais, e corroborar a ideia de que, apesar de mudanças na atuação, o Estado não perdeu centralidade no comando da economia brasileira.

Palavras-chave: Setores Estratégicos. Banco Nacional de Desenvolvimento Econômico e Social.

Laços corporativos. Holding EBX.
\end{abstract}

\begin{abstract}
The National Bank for Economic and Social Development (BNDES) has been playing a relevant role with long-term financing to large national companies, from the years 2000. Even after privatization, when it ceased to be the state-business, the public sector remains an important officer of the Brazilian productive structure. This article analyses how the BNDES, a subsidiary of shareholding, BNDESPAR, pension funds and private companies are central actors in the understanding of networks owners in Brazil. The expansion of the EBX Group in strategic sectors the data presented on BNDES disbursements and important political alliances of the entrepreneur Eike Batista help illustrate the dynamics of ties between state and domestic private companies, and corroborate the idea that even though changes in performance, the State has not lost centrality in command of the Brazilian economy.
\end{abstract}

Keywords: Strategic Sectors. National Bank for Economic and Social Development. Corporate bonds. Holding EBX.

\section{Introdução}

A emergência do desenvolvimento brasileiro que colocou o país na posição de $6^{\text {a }}$ economia do mundo no ano de 2012 se deu a partir de uma reestruturação produtiva, econômica e financeira que se consolidou nos anos 2000. Gargalos na infraestrutura e a retomada do discurso nacionalista de recuperação do crescimento econômico marcaram os anos Lula por meio de investimentos diretos e indiretos em grandes projetos de investimentos (GPI's) que, realizados tanto 
pelo setor público quanto pela iniciativa privada, receberam financiamentos do Banco Nacional de Desenvolvimento (BNDES).

Ao analisar a configuração produtiva brasileira após as mudanças dos anos de 1990, quando o Estado deixou de ser o Estado-empresário e passou o controle dos setores mais expressivos da economia à iniciativa privada, muita questões aparecem: Permanece o Estado sendo o grande financiador dos empreendimentos, agora majoritariamente conduzidos pela iniciativa privada? Qual é o papel do BNDES, na sua essência de banco público, mediante essa nova realidade de financiamento de empreendimentos privados? Tornou-se ainda mais forte 0 entrelaçamento do Estado com os grupos privados?

Nos anos 2000, o banco, que ultrapassou o Banco Mundial no aporte de recursos, passou a ser mais estratégico ainda na consolidação de grandes empresas, seja como financiador direto dos investimentos privados de longo prazo, ou como sócio por meio de sua subsidiária de participações, o BNDESPAR. Muitas empresas e grupos que passaram por fusões, tornaram-se conglomerados e internacionalizaram-se, passando a ser chamados de "Campeões Nacionais". Com esse novo desempenho de alocação de investimentos atrelado às estratégias de concentração de capital de grandes empresas privadas, o BNDES tem tido sua essência de banco público de desenvolvimento questionada (TAUTZ, SISTON, PINTO, 2011). Os temas sobre os critérios quanto à destinação dos recursos, à transparência e à responsabilidade socioambiental dos empreendimentos financiados concentram os debates atuais sobre o BNDES.

O presente texto traz como estudo de caso o histórico do grupo EBX, do empresário Eike Batista, caracterizando-o como grupo privado nacional que passou a atuar em setores considerados estratégicos, que foram desestatizados, tais como mineração, energia, logística portuária e construção naval. A partir dos anos 2000, a estabilidade da moeda, a retomada do crescimento econômico pelo governo federal, por meio de políticas como o aumento de recursos do BNDES e a criação de programas como o Programa de Aceleração do Crescimento (PAC), abriram um ambiente favorável às empresas privadas depois de quase duas décadas de escassos investimentos do governo. Eike Batista aproveitou as oportunidades conjunturais da política interna brasileira e passou a diversificar os negócios do grupo EBX, antes concentrados no ramo do ouro. Aportes bilionários foram liberados para o grupo EBX, colocando o empresário em evidência nacional e internacional. A jovem trajetória do grupo, porém, registra momentos bastante diversos como a arrecadação recorde de capital em oferta pública das empresas, entre os anos de 2006 e 2008, e a desvalorização e transferência de empresas em estágio pré-operacionais, a partir do $2^{\circ}$ semestre de 2012.

\section{O papel do Banco Nacional de Desenvolvimento Econômico e Social (BNDES) como financiador dos investimentos de longo prazo no período pós anos 2000}

O BNDES completou, em 2012, 60 anos. Ao longo de sua história, as orientações de apoio financiador do banco foram constantemente modificadas conforme o período político brasileiro e a configuração técnica do espaço 
produtivo nacional. Diferentemente da maioria dos bancos de desenvolvimento criados no mundo no período entre guerras e do pós-guerra, o BNDES não teve, na sua origem, o objetivo de reconstruir a economia de um país arrasado pela guerra como foi o caso dos países europeus e do Banco Internacional de Reconstrução e Desenvolvimento (BIRD), em 1946. O banco de desenvolvimento brasileiro é decorrente da necessidade de fortalecer a economia interna, de financiar em períodos longos a infraestrutura necessária ao crescimento industrial, histórico comum aos países de industrialização tardia na América Latina e na Ásia e a respectiva criação de suas instituições de fomento.

A trajetória do BNDES está diretamente ligada à integração do território nacional por ser a instituição chave no planejamento dos espaços produtivos pela atividade industrial e pelos projetos de desenvolvimento. Inicialmente projetado para apoiar o processo de substituição de importações sob o tripé capital estatal, privado nacional e capital privado multinacional, o banco sempre esteve à frente da infraestrutura e da base demandada para o crescimento da indústria no país. Destarte, entender o papel do banco em cada fase de crescimento econômico nessas suas seis décadas de existência, nos dá pistas concretas de como o Brasil foi se consolidando na economia internacionalizada e quais foram as estratégias governamentais que contribuíram para o cenário que se apresenta no século XXI.

Com quadros técnicos de excelência e com estratégicas informações e dados sobre o Brasil, a agência esteve presente nos principais projetos e planos de desenvolvimento no país como: o Programa de Reestruturação Econômica (PRE), o Plano de Metas (PM), o II Plano Nacional de Desenvolvimento (II PND), Plano Nacional de Desestatização (PND) e agora no PAC. O BNDES foi e continua sendo o único banco público de desenvolvimento no país com financiamentos de longo prazo.

Analisa-se, neste artigo, a instituição BNDES, destacando-o enquanto banco de desenvolvimento com performance robusta no aporte de recursos, e sua importância com os financiamentos de longo prazo às grandes empresas privadas nacionais a partir dos anos 2000. Dentro desse contexto, busca-se compreender um pouco mais sobre as redes que entrelaçam o Estado e a estruturação econômica e financeira de grupos privados e seus grandes empreendimentos recentes como os do grupo EBX, concentrados em setores estratégicos brasileiros antes monopolizados por empresas públicas.

O perfil que o BNDES assumiu nos anos 2000 é resultado da consolidação do processo, culminante nos anos de 1990, de privatizações de empresas públicas, liberalização da economia e ampliação da internacionalização da nossa economia. Resulta desse período o fortalecimento de grandes empresas e conglomerados, além do crescente protagonismo dos fundos de pensão de instituições públicas que passam a atuar como player estratégico na composição acionária e redes de propriedade que se formam no Brasil. É nessa primeira década dos anos 2000 que o aporte de recursos do BNDES cresceu exponencialmente. Tendo como marco o primeiro governo de Luís Inácio Lula da Silva (2003-2006), no qual os valores foram sendo elevados gradativamente, chama a atenção o incremento de mais de $100 \%$ no valor dos desembolsos entre o início e final do segundo mandato de Luís Inácio Lula da Silva (2007-2010), conforme podemos inferir na tabela 1. 
O BNDES chega aos anos 2000 com o papel consolidado e preponderante do direcionamento do crédito para empresas de diversos segmentos, além de atuar com participações acionárias consideráveis, por intermédio do BNDESPAR, em empresas de grande porte tanto privadas, como a Vale, como públicas, como é o caso da Petrobras. O banco brasileiro de desenvolvimento encerra a primeira década do século XXI como o maior banco do mundo com financiamentos superiores aos concedidos pelos bancos internacionais de fomento, o BIRD e o Banco Interamericano de Desenvolvimento (BID). Segundo os relatórios anuais do BNDES referentes a 2011 e 2012, o ano de 2010 teve a marca máxima referente aos desembolsos de $R \$ 168,4$ bilhões, enquanto no ano de 2011, houve uma pequena queda para $R \$ 139,7$ bilhões. No ano de 2012 , as aprovações de crédito chegaram a $R \$ 156$ bilhões.

Tabela 1. Evolução do Desembolso do Banco Nacional de Desenvolvimento Econômico e Social (BNDES) - (2000 - 2011)

\begin{tabular}{c|c}
\hline Ano & Bilhões R\$ \\
\hline 2000 & 23,4 \\
\hline 2001 & 25,7 \\
\hline 2002 & 35,1 \\
\hline 2003 & 38,2 \\
\hline 2004 & 40,0 \\
\hline 2005 & 47,1 \\
\hline 2006 & 52,3 \\
\hline 2007 & 64,9 \\
\hline 2008 & 92,2 \\
\hline 2009 & 137,4 \\
\hline 2010 & 168,4 \\
\hline 2011 & 139,7 \\
\hline 2012 & 156,0 \\
\hline
\end{tabular}

Fonte: BNDES, 2002.

Luciano Coutinho, nomeado presidente do banco em 2007 por Luís Inácio Lula da Silva, justifica no relatório anual de 2011 que a redução dos investimentos no último ano resulta de uma tendência de estabilização depois de desembolsos recordes nos anos de 2009 e 2010, período de esforço contracíclico do governo perante a crise de 2008 que abateu economias no mundo todo. $O$ presidente do banco resume que entre os motivos de elevados recursos nesses anos estão a operação de capitalização da Petrobras, a elevação da taxa de investimento geral na economia e a ampliação na participação das empresas. 
Enfatizando a prerrogativa de banco de desenvolvimento, Coutinho cita, também no relatório de 2011, que os financiamentos do BNDES equivaleram a $21 \%$ da Formação Bruta de Capital Fixo (FBCF), no país e que, por meio dos empreendimentos foram gerados direta e indiretamente 4,8 milhões de empregos naquele ano.

Importante ressaltar que os elevados aportes do BNDES nos anos 2000 marcam uma característica conservadora do nosso desenvolvimento, mas que se encaixa na dinâmica atual da economia brasileira que se tornou a $6^{\circ}$ maior do mundo no ano de 2012. A característica que se conserva é o fato do capitalismo brasileiro continuar a contar com o forte braço financiador do Estado, ou seja, permanece a vinculação em relação à máquina pública, a velha função de Estado subsidiador, que remonta aos tempos do Império. Entretanto, apesar de não ser mais o Estado-empresário, o Estado não perdeu centralidade. A relação do setor produtivo com o Estado, hodiernamente, se dá primordialmente pelos financiamentos diretos e indiretos e pelas participações acionárias.

O BNDES, com o aumento do seu aporte de recursos e diversificação nas formas de participação, principalmente por intermédio do BNDESPAR, tornou-se, além de financiador, sócio ativo de diversas empresas, apresentando desempenho econômico expressivo. Segue abaixo, tabela com os principais indicadores econômicos do BNDES nos últimos cinco anos. 
Tabela 2. Principais indicadores do Banco Nacional de Desenvolvimento Econômico e Social (BNDES) - 2007 a 2011

\begin{tabular}{|c|c|c|c|c|c|}
\hline \multicolumn{6}{|c|}{ Balanço Patrimonial em R\$ Milhões } \\
\hline & 2007 & 2008 & 2009 & 2010 & 2011 \\
\hline \multirow[t]{2}{*}{ Ativo total } & 202.65 & 277.294 & 386.633 & 549.020 & 624.827 \\
\hline & 2 & & & & \\
\hline \multirow{2}{*}{$\begin{array}{l}\text { Carteira de crédito e } \\
\text { repasses }^{[1]}\end{array}$} & 164.52 & 215.989 & 283.671 & 361.575 & 425.518 \\
\hline & 7 & & & & \\
\hline Participações Societárias ${ }^{[2]}$ & 18.983 & 25.293 & 34.012 & 107.476 & 99.601 \\
\hline Carteira de debêntures ${ }^{[1]}$ & 6.068 & 7.733 & 12.176 & 17.839 & 18.127 \\
\hline $\begin{array}{l}\text { Outros títulos e valores } \\
\text { mobiliários }\end{array}$ & 7.685 & 15.164 & 42.035 & 32.183 & 55.812 \\
\hline Outros ativos & 5.299 & 13.115 & 14.739 & 29.947 & 25.769 \\
\hline \multirow[t]{2}{*}{ Passivo total } & 202.65 & 277.294 & 386.633 & 549.020 & 624.827 \\
\hline & 2 & & & & \\
\hline \multirow[t]{2}{*}{ FAT/PIS-Pasep } & 133.84 & 146.088 & 152.540 & 163.091 & 177.947 \\
\hline & 9 & & & & \\
\hline Tesouro Nacional & 13.896 & 43.207 & 144.213 & 253.058 & 310.774 \\
\hline $\begin{array}{l}\text { Outras fontes } \\
\text { governamentais }{ }^{[3]}\end{array}$ & 8.356 & 22.381 & 18.541 & 19.857 & 21.896 \\
\hline $\begin{array}{l}\text { Operações } \\
\text { compromissadas }\end{array}$ & - & 8.447 & 13.741 & - & 7.808 \\
\hline Emissão de debêntures & 2.026 & 2.302 & 3.599 & 6.277 & 6.277 \\
\hline Captações no exterior & 12.084 & 17.486 & 16.463 & 19.778 & 22.449 \\
\hline Outras obrigações & 7.518 & 12.116 & 9.908 & 21.060 & 16.664 \\
\hline Patrimônio líquido & 24.923 & 25.267 & 27.628 & 65.899 & 61.012 \\
\hline Lucro líquido & 7.314 & 5.313 & 6.735 & 9.913 & 9.048 \\
\hline $\begin{array}{l}\text { Resultado de operações } \\
\text { financeiras }\end{array}$ & 4.782 & 3.867 & 5.821 & 7.039 & 6.488 \\
\hline $\begin{array}{l}\text { Resultado com provisão } \\
\text { para risco de crédito }\end{array}$ & 1.383 & 445 & (6) & 2.852 & 717 \\
\hline $\begin{array}{l}\text { Resultado de participações } \\
\text { societárias }\end{array}$ & 6.104 & 6.024 & 3.990 & 6.159 & 6.962 \\
\hline Despesas tributárias & (3.159) & (2.425) & (2.784) & (4.879) & (3.549) \\
\hline Outras receitas/(despesas) & $(1.796)$ & (2.598) & $(286)$ & $(1.258)$ & $(1.570)$ \\
\hline
\end{tabular}

Fonte : BNDES -Relatório Anual 2011.

1. Líquida de provisão para risco de crédito.

2. Inclui investimentos em sociedades não coligadas, coligadas e outros investimentos.

3. Inclui recursos do FGTS, FI-FGTS, FMM (Fundo de Marinha Mercante), FND (Fundo Nacional de Desenvolvimento) e outros fundos financeiros de desenvolvimento.

Conforme se pode inferir na tabela acima os indicadores do BNDES são bastante positivos. Com aumentos expressivos nas participações societárias e nas captações no exterior ${ }^{1}$, o valor passou de $\mathrm{R} \$ 22$ bilhões. O lucro líquido do BNDES,

1 Em 2009, o BNDES abriu uma subsidiária em Londres, a BNDES Limited. A empresa de investimentos visa adquiri participações acionárias em outras empresas, além de captar recursos no 
que somou mais de $R \$ 9$ bilhões em 2011, foi de $R \$ 8.183$ milhões em 2012. Importante notar que o expressivo aporte de recursos públicos que vem do Fundo de Amparo ao Trabalhador (FAT) e do Programa de Integração Social (PIS) e Programa de Formação do Patrimônio do Servidor Público (PASEP) manteve-se com certa estabilidade, aumentando gradativamente. Já o aporte do Tesouro Nacional passou de pouco mais de $R \$ 13$ bilhões para mais de $R \$ 310$ bilhões $^{2}$. Esse montante advindo de arrecadação de fundo dos trabalhadores e do Tesouro Nacional, tem alimentado críticas de diversos analistas que julgam que os créditos do BNDES deveriam ter critérios mais amplos que apenas os baseados no lucro a ser retornado pelos investimentos (Project finance), e acusam a política do banco de ser similar a de uma instituição privada focada nos retornos financeiros em detrimento de segmentos e portes de empresas de maior vulnerabilidade e relevância social.

No trecho a seguir, Lazzarini analisa como os recursos dos trabalhadores que poderiam ser utilizados pelo consumo das famílias são redirecionados para subsidiar investimentos:

Em outras palavras, os trabalhadores e suas famílias poupam compulsoriamente - consomem menos agora - para financiar projetos aprovados pelo governo - projetos que, espera-se, resultarão em desenvolvimento econômico futuro ("mais PIB potencial") (LAZZARINI, 2011, p. 50)

Ainda sobre a origem dos recursos, Lazzarini, comenta que o governo emite títulos da dívida pública para financiar o banco. Isso significa que o governo está criando dívida para financiar projetos e, considerando que a maior parte dos recursos vai para empresas de grande porte, inclusive privadas, o governo estaria, assim, apoiando a consolidação de grandes empresas chamadas de "Campeões Nacionais". O argumento do governo em apoiar aquisições e fusões está em fortalecer empresas nacionais no cenário nacional e na economia global.

Em artigo do Jornal O Globo, do dia 16/06/2012, especialistas divergem na análise sobre o BNDES. Maurício Canêdo, professor do Instituto Brasileiro de Economia, Fundação Getúlio Vargas (IBRE-FGV), diz que o BNDES está fornecendo créditos que poderiam vir dos bancos privados. Já Demian Fiocca, ex-presidente do banco, discorda afirmando que projetos de longa maturação não se sustentariam com os juros dos bancos privados. Sobre a participação em grandes negócios, o também ex-presidente do banco, Edmar Bacha, diz que "O BNDES deveria ter participação zero em aquisições e fusões e na escolha de campeões setoriais, além de desfazer toda a carteira do BNDESPAR que não se justifica atualmente devido ao volume do mercado de ações brasileiro". Reforça que, quando o governo torna-se sócio de empresas, conflitos de interesses surgem e que o governo pode

mercado. O banco também abriu uma filial em Montevidéu. A captação de recursos também acontece com a emissão de títulos de dívida e acordos firmados com outros bancos de desenvolvimento e até bancos privados.

${ }^{2}$ No ano de 2010, o Tesouro nacional passou a ser o principal credor do BNDES, responsável por aproximadamente $49,7 \%$ do passivo total do banco no final de 2011. Fonte: BNDES - Relatório Anual 2011. 
apoiar grandes grupos para disputar internacionalmente, mas que não deve fortalecer monopólios.

É possível verificar a distribuição dos desembolsos por porte de empresa ${ }^{3}$ por meio do relatório do BNDES. Segue a tabela 3 com a evolução dos financiamentos:

Tabela 3. Participação do desembolso do Banco Nacional de Desenvolvimento Econômico e Social (BNDES) segundo porte de empresa em anos selecionados

\begin{tabular}{l|c|r|c|r|r|r|r|r}
\hline \multirow{2}{*}{ Discriminação } & \multicolumn{2}{|c|}{2002} & \multicolumn{2}{c|}{2005} & \multicolumn{2}{c|}{2008} & \multicolumn{2}{c}{2011} \\
\cline { 2 - 9 } & $\begin{array}{c}\mathrm{R} \$ \\
\text { milhões }\end{array}$ & $\%$ & $\begin{array}{c}\mathrm{R} \$ \\
\text { milhões }\end{array}$ & $\%$ & $\begin{array}{c}\mathrm{R} \$ \\
\text { milhões }\end{array}$ & $\%$ & $\mathrm{R} \$$ milhões & $\%$ \\
\hline Micro e Pequena & $2.440,50$ & 7 & $4.013,90$ & 9 & $9.126,10$ & 10 & $27.450,20$ & 20 \\
\hline Média & $2.367,60$ & 6 & $3.767,70$ & 8 & $8.505,30$ & 9 & $13.995,10$ & 10 \\
\hline Subtotal & $4.808,20$ & 13 & $7.781,60$ & 17 & $17.631,40$ & 19 & $41.445,30$ & 30 \\
\hline Pessoa Física & $3.529,10$ & 9 & $3.880,30$ & 8 & $4.214,80$ & 5 & $8.347,80$ & 6 \\
\hline MPME & $8.337,30$ & 22 & $11.661,90$ & 25 & $21.846,20$ & 24 & $49.793,10$ & 36 \\
\hline Grande & $29.082,00$ & 78 & $35.318,40$ & 75 & $69.031,70$ & 76 & $89.080,30$ & 64 \\
\hline Total & $37.419,00$ & 100 & $46.980,20$ & 100 & $90.877,90$ & 100 & $138.873,40$ & 100 \\
\hline
\end{tabular}

Fonte: BNDES -Relatório Anual 2011.

Como já foi conferido na Tabela 2, de evolução dos desembolsos, os mesmos tiveram incremento expressivo a partir do ano de 2008, com recordes em 2009 e 2010. Importante notar que por todo esse período a priorização de recursos para as grandes empresas foi mantida ${ }^{4}$. Essa relação com as grandes empresas chamou a atenção dos especialistas e críticos que cobravam mais transparência do banco e denunciavam o favorecimento de grandes grupos empresariais.

Mediante pressão, inclusive de instituições de representatividade civil como a Plataforma BNDES, criada pelo Instituto Brasileiro de Análises Sociais e Econômicas (IBASE), no ano de 2011, houve redistribuição dos recursos destinados para as grandes empresas. Os desembolsos saíram da faixa acima de $70 \%$ do total predominante nos anos 2000 e caíram para 64\%. Apesar do aumento de aproximadamente $\mathrm{R} \$ 20$ bilhões para empresas de grande porte, o incremento de mais de $\mathrm{R} \$ 18$ bilhões direcionados basicamente para ampliação do crédito às

\footnotetext{
${ }^{3}$ O BNDES classifica as empresas por porte de acordo com a receita operacional bruta anual: Microempresa: menor ou igual a $R \$ 2,4$ milhões

Pequena empresa: Maior que $R \$ 2,4$ milhões e menor ou igual a $R \$ 16$ milhões

Média Empresa: Maior que $\mathrm{R} \$ 90$ milhões e menor ou igual a $\mathrm{R} \$ 90$ milhões

Média-grande Empresa: Maior que $R \$ 90$ e milhões e menor ou igual a $R \$ 300$ milhões

Grande Empresa: Maior que $\mathrm{R} \$ 300$ milhões

${ }^{4}$ Segundo artigo do Jornal O Globo de 18/12/2011, nos últimos 5 anos, as empresas mais favorecidas e que tornaram-se "multinacionais verde-amarelas" foram os frigoríficos JBS e Mafrig, a Oi, A BRF Brasil Foods, a Fibria (Votorantin) e a AMBEV. O total destinado a essas empresas chega a $R \$ 24,078$ bilhões. Já as participações acionárias no JBS, Mafrig, Fibria e Oi, somou R\$ 16,708 bilhões.
} 
pequenas empresas representaram $20 \%$ dos financiamentos totais do banco. Feito que significa um salto visto que, na década anterior, a fatia destinada às Micro e Pequenas empresas não passava de $10 \%$.

Os desembolsos do banco também são desigualmente destinados entre os ramos de atividade. Na tabela 4 a seguir, que seleciona os anos de 2008 a 2011, anos de elevação considerável dos financiamentos por conta da crise mundial, podemos identificar que a maior parte dos desembolsos concentra-se na indústria e infraestrutura. Destacam-se os setores de energia elétrica, ferrovias, siderurgia, química e petroquímica. Esse panorama reforça o papel do banco em atuar em momentos de crise, o que o governo chama de "esforço contracíclico", prover as indústrias nacionais que passaram a promover mais fusões e internacionalizar-se, e garantir a ampliação da infraestrutura necessária tornar o Brasil mais competitivo.

Tabela 4. Desembolsos do Banco Nacional de Desenvolvimento Econômico e Social (BNDES) por Ramo de Atividade

\begin{tabular}{l|r|r|r|r|r|r|r}
\hline Ramo de atividade & \multicolumn{3}{l}{ R\$ bilhões } \\
\cline { 2 - 8 } & 2008 & $\mathbf{2 0 0 9}$ & $\mathbf{2 0 1 0}$ & $\mathbf{2 0 1 1}$ & $\begin{array}{r}\text { 2009- } \\
\text { (em \%) }\end{array}$ & $\begin{array}{r}\mathbf{2 0 1 0} \\
\mathbf{2 0 0 9}\end{array}$ & $\begin{array}{r}\mathbf{2 0 1 1 -} \\
\mathbf{2 0 1 0}\end{array}$ \\
\cline { 2 - 8 } Indústria & 39,0 & 63,5 & 54,0 & 43,8 & 62,8 & 15,0 & 18,9 \\
\hline Infraestrutura & 35,1 & 48,7 & 52,4 & 56,1 & 38,6 & 7,8 & 7,0 \\
\hline Comércio/serviços & 11,2 & 17,3 & 27,1 & 29,2 & 55,2 & 56,4 & 7,7 \\
\hline Agricultura & 5,6 & 6,9 & 10,1 & 9,8 & 22,5 & 47,7 & 3,2 \\
\hline $\begin{array}{l}\text { Outras operações } \\
\text { de mercado }\end{array}$ & 1,4 & 1,0 & 24,8 & 0,8 & 23,4 & $2.275,7$ & 96,8 \\
\hline Total & 92,2 & 137,4 & 168,4 & 139,7 & 49,0 & 22,6 & 17,1 \\
\hline
\end{tabular}

Fonte: BNDES -Relatório Anual 2011

Outro aspecto é a distribuição dos desembolsos em nível das grandes regiões geográficas, conforme tabela 5. Esses números confirmam a histórica concentração econômica das atividades produtivas que ainda está nas regiões Sul e Sudeste, sobretudo em São Paulo, além de inúmeros Grandes Projetos de Investimentos inclusive no Estado do Rio de Janeiro. Em seguida, na terceira posição, temos a participação do Nordeste. As causas desse aumento sensível no Nordeste estão na instalação de plantas industriais que têm aproveitado condições fiscais atraentes e posição geográfica que diminui o custo do frete nas exportações, além ser apontado pela imprensa e especialistas como consequência, também, da atenção que o presidente do BNDES, Luciano Coutinho, pernambucano, tem dado à região. No Centro-Oeste, os investimentos que se destinam, principalmente, ao agronegócio, foram reduzidos, retornando a região ao percentual de $8 \%$. Já o aumento, chegando a $8 \%$, na Região Norte, acontece principalmente pelos projetos de energia. 
Tabela 5. Participação do desembolso do Banco Nacional de Desenvolvimento Econômico e Social (BNDES) por Região em anos selecionados

\begin{tabular}{l|r|r|r|r|r|r|r|r}
\hline \multirow{2}{*}{ Região } & \multicolumn{2}{|c|}{2002} & \multicolumn{2}{c|}{2005} & \multicolumn{2}{c|}{2008} & \multicolumn{2}{c}{2011} \\
\cline { 2 - 10 } & R\$ milhões & \% & R\$ milhões & \% & R\$ milhões & \% & R\$ milhões & \% \\
\hline Norte & $1.880,80$ & 5 & $1.615,80$ & 3 & $4.951,80$ & 5 & $10.864,40$ & 8 \\
\hline Nordeste & $3.783,70$ & 10 & $3.803,00$ & 8 & $7.627,20$ & 8 & $18.767,90$ & 14 \\
\hline Sudeste & $23.073,60$ & 62 & $28.739,80$ & 61 & $51.010,10$ & 56 & $68.238,10$ & 49 \\
\hline Sul & $6.091,80$ & 16 & $9.551,00$ & 20 & $17.407,60$ & 19 & $29.654,80$ & 21 \\
\hline Centro-Oeste & $2.589,30$ & 7 & $3.270,60$ & 7 & $9.881,30$ & 11 & $11.348,30$ & 8 \\
\hline Total & $\mathbf{3 7 . 4 1 9 , 3 0}$ & 100 & $46.980,20$ & 100 & $90.877,90$ & 100 & $138.873,40$ & 100 \\
\hline
\end{tabular}

Fonte: BNDES -Relatório Anual 2011.

Como a ênfase neste trabalho é relacionar atuação do Estado e das empresas privadas por meio do estudo de caso do grupo EBX na estrutura produtiva brasileira, destaca-se, também, o papel do BNDES no provimento de financiamentos dos projetos de investimento em infraestrutura previstos dentro PAC.

O PAC, que foi lançado em 2007, no final, portanto, do segundo mandato do Presidente Lula, está atualmente na sua versão 2, com investimentos previstos até 2014. Os investimentos são para empreendimentos públicos e privados. De acordo com tabela 7, a seguir, que expõe a carteira do BNDES no PAC, é possível verificar que a maior parte dos projetos é na área de energia (geração e transmissão de energia elétrica e petróleo e gás), seguida da logística com projetos de rodovias, ferrovias e portos. Ainda estão previstos no PAC, infraestrutura social e urbana voltada principalmente para ampliação do saneamento básico, urbanização, sobretudo em áreas metropolitanas, e ampliação do metrô.

Tabela 6. Carteira do Banco Nacional de Desenvolvimento Econômico e Social (BNDES) no Plano de Aceleração do Crescimento (PAC)

\begin{tabular}{l|r|r|r|r}
\hline Eixos & $\begin{array}{l}\text { Número de } \\
\text { projetos }\end{array}$ & $\begin{array}{l}\text { Investimento total } \\
\text { (R\$ milhões) }\end{array}$ & $\begin{array}{l}\text { Participação do } \\
\text { BNDES (R\$ } \\
\text { milhões) }\end{array}$ & $\begin{array}{l}\text { Desembolsos } \\
\text { 2011 (R\$ } \\
\text { milhões) }\end{array}$ \\
\hline Energia & 310 & 258.811 & 137.240 & 14.763 \\
\hline Logística & 94 & 49.888 & 31.314 & 3.600 \\
\hline $\begin{array}{l}\text { Infraestrutura } \\
\text { social e urbana }\end{array}$ & 85 & 18.462 & 10.667 & 1.447 \\
\hline $\begin{array}{l}\text { Administração } \\
\text { pública }\end{array}$ & 14 & 196 & 166 & 18 \\
\hline Total & 503 & 327.357 & 179.387 & 19.827 \\
\hline
\end{tabular}

Fonte: BNDES -Relatório Anual 2011. 
Sobre os desembolsos do BNDES no PAC até 2011, apresentamos também a distribuição regional dos mesmos na tabela 7:

Tabela 7. Distribuição Regional da Carteira do Banco Nacional de Desenvolvimento Econômico e Social (BNDES) no Plano de Aceleração do Crescimento (PAC) até 2011

\begin{tabular}{|c|c|c|c|c|c|c|c|c|}
\hline Eixos & Norte & Nordeste & Sudeste & Sul & $\begin{array}{c}\text { Centro- } \\
\text { Oeste }\end{array}$ & Inter-regional & Total & $(\%)$ \\
\hline Energia & 20.095 & 22.342 & 9.716 & 7.243 & 4.457 & 20.660 & 84.512 & 80,6 \\
\hline Logística & 58 & 2.299 & 7.646 & 807 & 251 & 2.042 & 13.103 & 12,5 \\
\hline $\begin{array}{l}\text { Infraestrutur } \\
\text { a social e } \\
\text { urbana }\end{array}$ & 204 & 543 & 5.714 & 558 & 91 & - & 7.111 & 6,8 \\
\hline Adm. Pública & 4 & 24 & 24 & 14 & 16 & - & 82 & 0,1 \\
\hline Total & 20.361 & 25.208 & 23.100 & 8.622 & 4.815 & 22.702 & 104.808 & 100 \\
\hline
\end{tabular}

Fonte: BNDES -Relatório Anual 2011.

Os números mostrados até aqui ilustram o quanto o Estado, por intermédio do BNDES e dos projetos governamentais de apoio à infraestrutura e ao setor produtivo de um modo geral, tem dado suporte aos investimentos que elevaram o PIB e, consequentemente, a colocação privilegiada de nossa economia, em nível global, nos últimos anos. Retorna-se à ideia de que esse crescimento é, grande parte, consequência do apoio estatal ao setor produtivo, com especial destaque às grandes empresas nacionais. Muitas dessas grandes empresas brasileiras, beneficiadas pelos financiamentos e associações, tornaram-se conglomerados e passaram a atuar internacionalmente ${ }^{5}$.

Seguindo o objetivo de analisar o BNDES na perspectiva das relações do público e do privado, seguiremos o texto contextualizando o banco e seu alinhamento às estratégias de inserção competitiva em nível nacional e global, tanto do Estado como das empresas privadas.

\section{Os laços entre Estado e Capital Privado}

Utilizaremos aqui, com os devidos créditos, a expressão "Laço" a partir da formulação de Sérgio Lazzarini, que lançou em 2011, o livro Capitalismos de laços - os donos do Brasil e suas conexóes. Em seu livro, Lazzarini define laço como uma forma genérica para "relação entre atores sociais para fins econômicos". Ao analisar as relações entre capital privado e capital público, o autor questiona se o

\footnotetext{
${ }^{5}$ Com a justificativa de fortalecer a competitividade das empresas brasileiras foi inaugurada, em 2003, com alteração no estatuto do BNDES, linha de crédito para internacionalização das empresas. A relação da internacionalização das empresas com o desenvolvimento do país seria o aumento das exportações; a transferência de tecnologia e a repatriação de divisas.
} 
grau de entrelaçamento societário que reproduz complexos grupos e "pirâmides" societárias, e que culmina muitas vezes em favorecimentos que perpassam mais pelo campo político do que pelos critérios técnicos, são legítimos ou disfunção do capitalismo.

Lazzarini cita as formulações de Raymundo Faoro, na obra Os donos do poder, lançada em 1957, para localizar as raízes do capitalismo de laços, ou seja, da imbricação entre Estado e interesses privados.

Faoro observa a formação de grupos sociais que se conectam intimamente no tecido público em um "jogo interno de vantagens". A sua interpretação da realidade brasileira é, assim, também calcada em bases relacionais. O poder, na concepção de Faoro, se sustenta, fundamentalmente, por meio de intricadas conexões - nas suas próprias palavras, uma rede patriarcal. Os donos do poder são aqueles que se beneficiam de uma dinâmica de laços (LAZZARINI, 2011, p.13)

O mesmo autor chama a atenção para o fato de que a centralidade do governo no setor produtivo não foi eliminada, mas consolidada na transição que se deu no período das privatizações com o Estado, deixando de ser o empresário e assumindo o comando burocrático e técnico do processo por meio do BNDES. E que, mesmo após a desestatização, o governo volta a firma-se ao financiar e fortalecer grandes empresas e tornar-se sócio de muitas delas. Lazzarini classifica como "notável" que nos dois momentos, o de intensificação das privatizações nos anos de 1990 e o dos generosos financiamentos às grandes empresas nos anos 2000, o governo se preserva e mantém os interesses das elites empresariais. Notável também pelo fato do entrelaçamento do interesse privado, viabilizado pelo aparato público, dar-se em governos de distintas origens ideológicas. É no governo do PT, porém, que o Estado é reforçado para além dos financiamentos e associações, mas voltando a fortalecer estatais e criar novas ${ }^{6}$.

Em relação à aproximação entre o Estado e as empresas privadas, há vários aspectos a se considerar. Uma política econômica voltada a incentivar o setor produtivo, principalmente o industrial, e oportunidades de crédito generosas são condições importantes e característica de muitas economias que prosperaram. Ao mesmo tempo, há que se atentar para a parcialidade no direcionamento dos recursos, no favorecimento mútuo entre governos e empresários, que mediante apoios, elegem os representantes que estarão inclinados a prover as condições necessárias ao crescimento dos negócios. O tema da desigualdade nos desembolsos direcionados para as grandes empresas e a consequente crítica dessa política do banco já foram citadas como bastante polêmicas. Um risco eminente, que reforça o debate, é que determinados governantes passem a manter, mediante os apoios aos seus projetos, um relacionamento colaborativo ou, até

\footnotetext{
${ }^{6}$ Segundo dados do Relatório Anual 2010 do Ministério do Planejamento, atualmente o Brasil conta com 122 estatais. Dessas empresas $84,4 \%$ estão ligadas ao setor produtivo enquanto $15,6 \%$ pertencem ao setor financeiro. Entre as empresas de maior patrimônio estão a Petrobras, a Eletrobras, CHESF e Furnas. Entre as instituições financeiras destacam-se o Banco do Brasil, A Caixa Econômica Federal e o próprio BNDES. Cabe destacar que o governo Fernando Henrique terminou, em 2001, com o saldo pós privatização de 108 estatais.
} 
mesmo, subserviente ao grande capital. Essa subserviência, inclusive, muitas vezes mascarada sob as bandeiras do desenvolvimento, é que tem sido conivente com inúmeros abusos quantos aos direitos dos cidadãos atingidos pelos grandes projetos de investimentos.

Esse é outro ponto que tem alimentado as críticas ao BNDES: a omissão quanto à responsabilidade sobre impactos ambientais dos empreendimentos que têm financiamentos aprovados pelo banco. Podemos destacar, como grandes empreendimentos que têm tido muita repercussão quanto aos impactos e crimes contra os direitos humanos nos locais onde se instalam, os casos da Usina Termoelétrica de Belo Monte, no Pará, o Complexo Logístico, Industrial e Portuário do Açu, no Norte Fluminense e a Companhia Siderúrgica do Atlântico, na Zona Oeste do Município do Rio de Janeiro. Há, ainda, denúncias de cunho trabalhista na Vale. A constatação, pelos movimentos sociais, pesquisadores e entidades civis, de que o BNDES, por meio de sua política de créditos, privilegia grandes grupos domésticos em detrimento dos interesses dos cidadãos impactados gerou diversos protestos ao banco durante a realização da Rio +20 , evento da ONU sobre o meio ambiente, realizado no Rio de Janeiro em julho de 2012.

As críticas ao banco se dão também pela falta de transparência da instituição. Até a Lei No 12.527, de 18 de novembro de 2011, o banco não divulgava o quantitativo e os desembolsos de forma nominal ou por CNPJ das empresas. Os relatórios anuais do BNDES apresentavam, como apresentam ainda, o desempenho do banco a partir de financiamentos agrupados por porte de empresa, setor de atividade ou região brasileira. A Lei de Acesso à Informação (LAI) possibilitou, inclusive, que boa parte dos dados referentes aos desembolsos para o grupo EBX fosse levantados para este trabalho. Sem a aprovação da lei, a pesquisa teria que se basear em relatórios trimestrais de cada uma das empresas, o que tornaria a tarefa hercúlea. A falta de transparência fez com que o BNDES fosse alcunhado como "caixa preta" e aqueceu o debate sobre a relação do governo com os grandes empresários, que, beneficiados com crescentes empréstimos e participações do BNDESPAR, tornavam-se os "Campeões Nacionais". Os critérios de financiamento estão no topo dos debates que envolvem o banco atualmente.

Como já introduzido, para garantir o acesso ao governo, muitos empresários estabelecem relações de apoio a políticos em eleições. Com doações em campanhas, o pacto entre empresários e políticos é reforçado, resultando em clientelismo e favorecimento a determinados proprietários. O favorecimento pode acontecer de diferentes formas: por meio de licitações tendenciosas, facilidades fiscais e acesso a financiamentos.

A dinâmica de laços e suas conexões no Brasil apresenta características bem definidas: a dinâmica das redes aglomeradas de proprietários seletos que envolvem setor público e privado nacional e internacional; a centralidade do Estado nessas redes; e o clientelismo reforçado pelos mútuos apoios entre empresários e políticos, pactuado sobretudo em campanhas eleitorais. Esse comportamento geral dos laços do capitalismo no Brasil baliza a análise proposta sobre as estratégias de crescimento do grupo EBX. Apresenta-se aqui breve histórico das empresas atuantes em setores considerados estratégicos, nos quais já predominaram as 
empresas estatais, bem como a relação do empresário brasileiro Eike Batista com o setor público, com destaque para os financiamentos oriundos do BNDES.

\section{Os laços entre o Grupo EBX e o Estado}

O grupo EBX teve, desde a sua origem e acelerada expansão, estreita relação com o Estado. A expansão do grupo nos setores estratégicos foi concentrada nos anos do governo de Luís Inácio Lula da Silva (2003 - 2010), período em que foi retomado o discurso do crescimento econômico no país. As empresas de infraestrutura foram criadas no período que vai de 2001 a 2009, sendo que somente a MPX Energia S.A. foi criada em 2001. Já o surgimento das MMX Mineração e Metálicos S.A., LLX Logística S.A., OGX Petróleo e Gás Participações S.A. e OSX Brasil S.A. concentrou-se entre os anos de 2005 a 2009. Nesses quatro anos, duas políticas do governo federal merecem destaque por terem sido propícias ao grupo EBX: os aumentos consideráveis dos desembolsos do BNDES para as grandes empresas e os investimentos do PAC nas áreas de logística e energia, principalmente petróleo e gás.

O projeto do Porto do Açu, por exemplo, da empresa LLX criada em 2007, acontece no mesmo ano em que os recursos do BNDES começaram a aumentar consideravelmente a partir da política adotada pelo novo presidente do banco, Luciano Coutinho, em apoiar empresas estratégicas para alavancar a economia. Apresentam-se aqui, para reforçar o tema dos recursos públicos em empreendimentos privados, os valores dos desembolsos do banco para as empresas da EBX. Os financiamentos para a LLX e OSX, com empreendimentos no Porto do Açu, vieram a partir de 2009 e, desde então, foram reforçados, chegando ao valor de aproximadamente $\mathrm{R} \$ 5$ bilhões até julho $2012^{7}$.

Já para o Porto Sudeste, os primeiros repasses foram em 2009 (R\$407,7 milhões) e 2010 ( $R \$ 808,4$ milhões), quando o mesmo ainda pertencia à empresa LLX. Já em abril de 2013, A MMX anunciou ter obtido novo financiamento do BNDES no valor de $\mathrm{R} \$ 935$ milhões. Com esse último valor aprovado, o desembolso total do BNDES para o Porto Sudeste passou de $\mathrm{R} \$ 2$ bilhões. Segundo o site da $M M X$, o investimento demandado pelo porto Sudeste é de $R \$ 2,4$ bilhões, sendo assim, o BNDES seria responsável por mais de $90 \%$ dos investimentos. Somando os recursos públicos, concedidos via financiamento direto do BNDES aos dois empreendimentos portuários do empresário Eike Batista, chegamos à cifra de $R \$ 7$ bilhões.

A MPX também obteve financiamento de longo prazo do BNDES para os projetos das Usinas Termelétricas (UTE) MPX Pecém II Geração de Energia, UTE Parnaíba e UTE Porto do Itaqui, no valor aproximado de $\mathrm{R} \$ 1,7$ bilhão.

\footnotetext{
${ }^{7}$ As informações sobre os empréstimos do BNDES Às empresas do grupo EBX foram recolhidas nas seguintes fontes: i) informados pelo próprio BNDES, através de solicitação, via e-mail para a pesquisa; ii)Relatórios trimestrais do BNDES; iii) site das empresas do grupo EBX.
} 
Segundo informação do próprio BNDES, em Julho de 2013, o montante de financiamentos aprovados pelo banco para o grupo EBX é de aproximadamente $R \$$ 10,4 bilhões, sendo $R \$ 6$ bilhões efetivamente contratados até o primeiro semestre de 2013.

O governo federal também aportou recursos nas empresas do grupo EBX por meio do BNDESPAR.

Tabela 8. Participação do BNDESPAR em empresas do grupo EBX

\begin{tabular}{l|c|c}
\hline Empresa & Participação (\%) & Valor/ R\$ Milhões \\
\hline CCX Carvão da Colômbia S.A. & 11,72 & 69 \\
\hline MMX Mineração e Metálicos S.A & 1,03 & 31 \\
\hline MPX Energia S.A. & 11,72 & 385 \\
\hline OGX Petróleo e Gás Participações S.A & 0,26 & 49,5 \\
\hline SIX semicondutores S.A. & 33,02 & 245 \\
\hline
\end{tabular}

Elaboração própria - Fonte: $2^{\circ}$ Relatório Trimestral 2012 - BNDESPAR.

Segundo o BNDES, em relatório trimestral de março de 2013, as participações do BNDESPAR nas empresas do grupo EBX representavam cerca de $0,6 \%$ do total do ativo da subsidiária do banco.

No ano de 2009, O BNDESPAR adquiriu ações da LLX por RS 150 milhões, com valor unitário de $R \$ 1,80$ em um contrato que já previa a subscrição de ações com cláusula da opção de recompra das mesmas pelo valor corrigido, mas sem considerar valor de mercado. Quatro meses depois as ações foram recompradas pela LLX pelo valor unitário de $R \$ 2,30$, quando seu valor no mercado era de $R \$$ 4,44. Nessa operação, os acionistas da LLX tiveram ganho de $R \$ 89,2$ milhões. Considerando que a LLX foi beneficiada por essa operação, a empresa e os gestores do BNDESPAR foram denunciados no Ministério Público por suspeita de favorecimento pessoal e atitude antieconômica. Em sessão de 28/09/2011 ${ }^{8}$, o Tribunal de Contas da União deu parecer desfavorável às acusações do Ministério Público.

O aporte de recursos nos empreendimentos do grupo EBX via BNDES e BNDESPAR, ilustram o quanto próxima tem sido a relação do empresário Eike Batista com o governo federal. Lazzarini (2011), inicia seu livro sobre o capitalismo de laços no Brasil citando que, interessado nas possíveis mudanças sobre o comando da Vale e na ampliação de acesso aos financiamentos do BNDES, Eike Batista se alinhou ao governo. Antes disso, destacou-se como o maior doador individual para a campanha de Lula em 2006 e foi o maior financiador privado do filme Lula, o filho do Brasil. Eike Batista também contribuiu com $R \$ 10$ milhões na Campanha do Rio à sede das olimpíadas de $2016^{9}$, sendo citado por Lula nos

\footnotetext{
${ }^{8}$ Disponível em http//: www.tcu.gov.br -Código eletrônico para localização na página do TCU na Internet: AC-2618-40/11-P.

9. Disponível em http://www.rio2016.com/noticias/noticias/eike-batista-abraca-a-campanha-rio2016
} 
agradecimentos durante discurso de comemoração da escolha do Rio pelo Comitê Olímpico em outubro de 2009. Nesse mesmo ano, recebeu os primeiros aportes do BNDES e, graças, também, à captação em bolsa de valores das suas empresas, passou a ser considerado o homem mais rico do Brasil.

Em 2010, depois de encontros pessoais com Lula, Eike Batista teve o projeto do Porto do Açu incluído no PAC. Nessa época, a atual presidente Dilma Roussef era Ministra da Casa Civil e avaliava o enquadramento de projetos ao programa. Em abril de 2012, já eleita presidente, Dilma Roussef visitou as obras do Porto em São João da Barra, oportunidade em que foi comemorado o início da produção de petróleo no campo de Waimea, Bacia de Campos, pela OGX. Em seu discurso, a presidente exaltou a contribuição das empresas do empresário Eike Batista para a economia brasileira, sobretudo da OGX. No governo Dilma Roussef, iniciado em 2011, as relações entre a EBX e o governo federal continuaram inabaladas com liberações de financiamentos do BNDES e aumento na participação pelo BNDESPAR nas empresas do grupo.

Ao entrar em negócios individualmente como estreante em empresas, muitas vezes em estágio pré-operacional, Eike Batista buscou parceiros que compusessem seus quadros como acionistas e/ou como sócios com o know how técnico necessário para fazer a atividade produtiva girar. O empresário também cita em seu livro que, por ser sempre o principal acionista de suas empresas, despertou a confiança necessária que resultou em sucesso na atração de seus sócios-parceiros. A conquista de sócios permitiu acumular capital inicial de investimento expressivo, e fez com que suas jovens empresas criadas aparecessem como grandes nos setores em que atuariam.

Destaque para o salto em recursos que tais empresas obtiveram a partir da abertura de seus capitais em bolsa de valores, mais precisamente, na IBOVESPA, entre os anos de 2004 e 2008. Nesse período, a oferta pública inicial de ações das empresas do grupo " $X$ " é um evento à parte pelo montante levantado em negócios que estavam ainda muito iniciais. A OGX, por exemplo, à época da sua oferta pública inicial, em 2008, não tinha sequer previsão precisa de início da produção de petróleo. Eike Batista incorporou mais ainda seu estilo "Midas" ao tornar-se destaque com a valorização bilionária de suas empresas que ofereciam de mais sólido aos investidores a assertiva otimista do seu maior acionista e controlador $^{10}$.

As ofertas públicas de ações que se seguiram foram da MMX em 2006, da MPX em 2007 e da OGX em 2008. No total foi captado R\$ 9,87 bilhões, o que representa $10 \%$ do total arrecadado por todas as empresas que abriram capital no período entre 2002 e 2009 (LAZZARINI, 2011). A OSX fez sua oferta pública em 2010, arrecadando o valor de $\mathrm{R} \$ 2.450 .400 .000,00$. Dentre os investidores estão pessoas físicas, jurídicas, investidores estrangeiros, fundos de pensão e previdência privada, clubes de investimentos e participantes de consórcios. Visto que a

10 No caso da OGX, parte da credibilidade inicial se deu pelo corpo técnico, oriundo da PETROBRAS, que Eike Batista conseguiu contratar. Destaque para a contratação do geólogo Paulo Mendonça que compunha a equipe do Pré-Sal na estatal. Após sua entrada, a recém criada OGX, participou da $10^{\mathrm{a}}$ rodada de leilões da ANP e arrematou 21 blocos. 
possibilidade de abertura de capital é uma estratégia importante para levantamento de caixa e valorização das ações das empresas, realçamos que este momento foi decisivo para o protagonismo do empresário Eike Batista que se tornou, com a totalização do montante, em 2008, o brasileiro mais rico.

O ano de 2012, porém, trouxe dificuldades ao grupo EBX, principalmente a partir dos anúncios de que a OGX cancelaria a produção de petróleo em campos considerados não comercialmente viáveis. Desde então, as ações despencaram e os prejuízos acumularam-se, encolhendo o caixa do grupo EBX. Dos 13 blocos arrecadados na $11^{\mathrm{a}}$ rodada de leilões da Agência Nacional do Petróleo, Gás Natural e Biocombustíveis (ANP), realizada em maio de 2013, a petroleira anunciou, em agosto do mesmo ano, que devolveria nove. A pulverização nos papéis da OGX afastou sócios investidores importantes, como a PETRONAS (petroleira malaia) e, a partir dos riscos de eminente "calote", colocou em evidência o debate sobre os grandes financiamentos que as empresas de Eike Batista receberam do BNDES.

No ano de 2013, a desconfiança de credores e acionistas abalou as empresas, resultou na saída de executivos, com mudanças nos conselhos, e despertou o interesse de investidores pelos ativos da instável EBX. A pressão por parte de acionistas que viram seus papéis desvalorizarem vertiginosamente e também a proximidade de datas de quitações de empréstimos com bancos como o Bradesco e o BNDES ${ }^{11}$ resultaram na venda majoritária das empresas e ativos do grupo. A MPX foi vendida à companhia elétrica alemã E.ON, e a LLX para o grupo estadunidense EIG. Pelo menos essas duas empresas abertas do grupo EBX já não estão mais sob controle do ex-bilionário Eike Batista, que também já deixou a presidência dessas empresas, permanecendo apenas como acionista.

É possível constatar na prática do grupo EBX que as ideias tanto de compartilhamento de riscos e oportunidades como da associação ou transferência de negócios e abertura de subsidiárias, presentes na concepção e atuação das empresas criadas a partir de 2000, tornaram-se evidentes sobretudo no momento de crise do grupo. A partir do colapso das empresas mais importantes do grupo EBX, o presidente do BNDES Luciano Coutinho foi convocado pelo Senado Federal brasileiro, em agosto de 2013, para dar explicações sobre o montante financiado às empresas de Eike Batista. Coutinho foi questionado sobre as operações de alto valor com o grupo EBX, de natureza privada, e riscos de prejuízos ao banco, que foram descartados pelo mesmo. Essa sessão no Senado Federal colocou na pauta do governo o tema, já evidenciado e tão enfaticamente denunciado por estudiosos e movimentos sociais, do financiamento público de grandes empresas privadas no Brasil.

${ }^{11}$ As dívidas do grupo EBX estão estimadas, segundo sites especializados em $R \$ 11$ bilhões. 


\section{Considerações finais}

A estrutura produtiva brasileira esteve, historicamente, sob a responsabilidade do Estado. O modelo de desenvolvimento orientado para as atividades industriais tem como referência inicial os anos de 1930, governo Vargas, com o processo de substituição de importações. O setor público passou a assumir a perspectiva do planejamento com a criação de empresas estatais em setores estratégicos e instituições que dessem apoio às ações governamentais. A criação do BNDES em 1952, segundo governo Vargas, estava nesse contexto de apoiar, por meio de financiamentos de longo prazo, o projeto de industrialização no país e de integrar o território.

A desestatização de setores estratégicos no Brasil, processada a partir dos anos 1990, como parte do receituário neoliberal, permitiu que empresas privadas nacionais ou estrangeiras assumissem ramos como energia, mineração, telecomunicações, transportes, entre outros. O ente público passou a fiscalizar o ente privado e mediar as condições técnicas e fiscais no atendimento aos interesses das empresas. Ao mesmo tempo, foram reduzidos os investimentos do governo nas áreas que ainda permaneceram sob a sua tutela, levando o país ao sucateamento no que tange à infraestrutura configurando gargalo que ameaçava o crescimento econômico. O discurso neoliberal do Estado mínimo reduziu a referência de Estado forte, ligado ao planejamento da economia e à presença robusta das empresas públicas, uma vez que essas características foram rotuladas como obsoletas frente às necessidades de inserção competitiva do Brasil na economia globalizada.

No governo Lula (2003-2010) a orientação neoliberal das privatizações é deixada de lado e o governo adota o discurso de retomada do crescimento econômico. Dentre as políticas governamentais, estava previsto o foco nos setores estratégicos à industrialização, fortalecendo tanto as empresas estatais que ainda restavam, especialmente a Petrobras, como as empresas privadas nacionais e estrangeiras. Como política de apoio às empresas privadas nacionais, o BNDES vem, a partir de 2007, aumentando o seu volume de recursos, superando os do Banco Mundial. O BNDESPAR também aumentou a participação em diversas empresas e o governo voltou a ter status de ator protagonista na economia.

Com o apoio estatal por meio dos financiamentos de longo prazo, planos de aceleração do crescimento da economia como o PAC e subsídios fiscais, algumas empresas privadas, que amargaram dificuldades com a liberalização da economia nos anos de 1990, voltaram a crescer, fundiram-se e até se internacionalizaram. Os altos financiamentos do BNDES a determinados grupos privados resultaram na criação de uma lista seleta de empresas brasileiras chamadas de "Campeãs Nacionais". Forma-se, no Brasil, uma rede de proprietários ainda mais restrita e aglomerada, da qual fazem parte as grandes empresas privadas e o governo através das estatais como a Petrobras, os fundos de pensão, e instituições como o BNDES e o BNDESPAR. 
Os empreendimentos das empresas MPX, MMX, LLX, OGX e OSX de Eike Batista cresceram em ritmo acelerado na medida em que encontraram espaço para produção em setores estratégicos com defasagem tais como: da energia elétrica e logística, e com demanda para exportação como é o caso da mineração. $E$, ainda, o incremento na exploração e produção de petróleo e gás e a consequente necessidade de equipamentos offshore. O empresário adotou como estratégias a associação com o capital internacional, a sinergia entre os negócios e o alinhamento ao governo federal que reverteu em vantajosos financiamentos de longo prazo.

O caso das empresas de infraestrutura, mineração e energia da EBX contextualiza a dinâmica de laços entre Estado e empresas privadas. O resultado disso tem sido o comprometimento do critério da impessoalidade no acesso a financiamentos, isenções fiscais e a influência em instituições governamentais. $O$ colapso do grupo EBX, a partir do segundo semestre de 2012, colocou na pauta os questionamentos sobre a opção do governo federal em beneficiar grandes empresas privadas. Os laços corporativos entre capital privado e o Estado, que marcam a atual dinâmica capitalista brasileira, são uma versão atualizada de traços de clientelismo e patrimonialismo na nossa sociedade.

\section{REFERÊNCIAS}

BATISTA, Eike. O X da Questão. Rio de Janeiro: Sextante, 2011.

BNDES. BNDES: 50 anos de Desenvolvimento. Rio de Janeiro, BNDES, 2002.

BNDES. Relatório Anual 2011. Rio de Janeiro: BNDES, 2011. Disponível em: http://www.bndes.gov.br. Acessado em 20/07/2012.

FAORO, Raymundo. Os Donos do Poder - Formação do Patronato político Brasileiro. $3^{\mathrm{a}}$ ed. Rio de Janeiro: Globo, 2001. Disponível em (http: //groups.google.com.br/group/digitalsource)

FURTADO, Celso. Pequena introdução ao desenvolvimento: enfoque interdisciplinar. São Paulo: Nacional, 1981.

GARCIA, Ana S. O BNDES e a expansão de empresas com sede no Brasil. Rio de Janeiro, 2011. Disponível em:( http// www.plataformabndes.org.br). Acessado em $20 / 05 / 2012$

LAMOSO, Lisandra Pereira. A infraestrutura como elemento organizador do território. In: SILVEIRA, Marcio Rogério, LAMOSO, Lisandra Pereira, MOURÃO, Fernando Cirino (Org.) Questões Nacionais e Regionais do Território Brasileiro. São Paulo: Expressão Popular: UNESP, 2009.

LAZZARINI, Sérgio G. Capitalismo de Laços: os donos do poder e suas conexões. Rio de janeiro: Elsevier, 2011.- $3^{a}$ reimpressão. 
MINISTÉRIO DO PLANEJAMENTO. PAC - Balanço 2010 - 4 anos. Disponível em (http://www.plnejamento.gov.br). Acessado em 14/10/2011.

NAJBERG, Sheila. Transformação do Sistema BNDES em Financiador do Setor Privado Nacional. Rio de Janeiro: BNDES, 1989.

PIQUET, Rosélia. Indústria e Território no Brasil Contemporâneo. Rio de Janeiro: Garamond, 2007.

ROSA, Bruno, BATISTA, Henrique. Grandes empréstimos, pequenos avanços BNDES destina $\mathrm{R} \$ 40$ bi para turbinar apenas seis empresas. Jornal O Globo. Rio de Janeiro, 18 de dezembro de 2011. Economia.

TAUTZ, Carlos; SISTON, Felipe; PINTO, João Roberto Lopes; BADIN, Luciana. 0 BNDES e a reorganização do capitalismo brasileiro: um debate necessário. Disponível em: http: www.plataformabndes.org.br. Acessado em 14/05/2012.

VELASCO JÚNIOR, Licínio. Privatização no Brasil: Privatização: Mitos e Falsas Percepções. Rio de Janeiro, BNDES, 1999.

Submetido em $26 / 11 / 2013$

Aprovado em 05/05/2015

Sobre a autora

Claudia de Oliveira

Mestre em Planejamento Regional e Gestão de Cidades

Docente no Instituto Federal Fluminense - IFF

Endereço: Av. Souza Mota, 350 - Parque Fundão. 8060-010 - Campos dos Goytacazes - RJ Brasil.

E-mail: coliveirageo@gmail.com 